\title{
Is mesenteric lymphadenitis a cause of ovarian reserve reduction? - Case Report
}

Ana Karina Bartmann $n^{1,2,3,4}$, Victor César de P S do Nascimento ${ }^{2,4}$, Lucas L M da Silva ${ }^{1,3}$, Denise Fabri R. E. Mello ${ }^{1,3}$, Jessica R Gualberto ${ }^{1}$, Daniela M Bertoncelo ${ }^{1}$, Karla Verônica S Millani' ${ }^{1}$, Isabele G. Sanchez ${ }^{1}$

\author{
${ }^{1}$ Assisted Reproduction Center - Department Gynecology and Obstetrics - Medical School - University of \\ Ribeirão Preto (UNAERP), Ribeirão Preto/SP - Brazil \\ ${ }^{2}$ Human Reproduction Center of the Ana Bartmann Clinic - Ribeirão Preto/SP - Brazil \\ ${ }^{3}$ National Council of Scientific and Technological Development (CNPq) - Brazil \\ ${ }^{4}$ Department of Biotechnology - University of Ribeirão Preto, Ribeirão Preto/SP - Brazil
}

\begin{abstract}
Mesenteric lymphadenitis is a clinical condition that affects mostly children and teenagers. Its symptoms include fever, severe abdominal pain, nausea, and, in some cases, diarrhea, constipation, and acute abdomen. This paper describes the case of a 16-year-old patient with mesenteric lymphadenitis submitted to an exploratory laparoscopy for suppurative lymph nodes that evolved to a drastic reduction of ovarian reserve. Because of the patients age, she was offered cryopreservation of her ovarian tissue.
\end{abstract}

Keywords: Mesenteric lymphadenitis, Infertility, Ovarian Tissue Freezing, Fertility Preservation, Ovarian Reserve

\section{INTRODUCTION}

Mesenteric lymphadenitis is a clinical condition characterized by fever, abdominal pain, nausea, and, in some cases, diarrhea and constipation. Depending on the age of the patient, these symptoms are often associated with upper respiratory infections such as pharyngitis (Asano, 2012). Yersinia enterocolitica is one of the main etiological agents, with higher incidence in children (Backhus et al., 2007; Bertelli et al., 2014)

Abdominal pain is usually acute, intense, and more diffuse when compared to other diagnoses of acute abdomen (Bratucu et al., 2014). Episodes of pain irradiate most often from the right lower quadrant and may be confused with acute appendicitis, although they may occur in other parts of the abdomen (Dare et al., 1989). Many patients end up being offered emergency surgery due to leukocytosis; however, the appendix is normal, while the ileocecal mesenteric lymph nodes are swollen and a small quantity of ascites is found (Garcia et al., 2007). In rare cases, patients may have suppurative lymphatic ganglia evolving to peritonitis (Asano, 2012, Groselj-Grenc et al., 2007). The clinical follow-up of individuals with acute abdominal pain usually takes into account clinical signs such as fever, vomiting, nausea, anorexia, and diarrhea. Additional work-up may aid the diagnosis of acute abdomen (Karmazyn et al., 2005). Abdominal ultrasound examination plays an important role in the diagnosis of lymphadenitis, as patients often present swollen mesenteric lymph nodes (Kovanci \& Schutt, 2015).

Female infertility has increased over time (Liao et al., 2011). Abdominal diseases such as tumors, and inflammatory and infectious processes such as appendicitis, pelvic inflammatory disease (PID), and endometriosis, may diminish ovarian function and decrease the chances of female patients becoming pregnant (Lucey et al., 2005; Martins et al., 2006).

There is no proven causal relationship between mesenteric lymphadenitis and infertility established in the literature. However, it is possible that complications of the disease, such as pelvic infection caused by suppurative lymph nodes, or complications from surgical procedures such as oophorectomy, oophoroplasty, and salpingectomy, may cause infertility or reduced fertility.

\section{CASE DESCRIPTION}

Patient GM, aged 16, came with her mother to a Human Reproduction Center to have her ovarian function assessed and to look into possible fertility preservation methods. The patient had undergone an exploratory laparotomy a year before for acute abdomen and a suspicion of appendicitis. She took birth control pills as a contraceptive method.

Total abdomen ultrasound examination performed during the procedure revealed a "solid, heterogeneous expansive formation, with areas of gross calcification inside and unclear borders measuring around $8.6 \times 4.4 \mathrm{~cm}$ in the right adnexal region, and an adjacent oval cyst formation with ill-defined wall and gross septa inside, measuring $5.8 \times 4.3 \mathrm{~cm} . "$ Lab work-up showed she had mild leukocytosis with a left shift, which caused her to be referred to an exploratory laparotomy.

During surgery her appendix was normal and the right adnexa was affected by swollen lymph nodes, some of which suppurative. The suppurative lymph nodes were excised and her ovaries were preserved, as she was a childless teenager. The patient stayed in the hospital for six days on antibiotics. She responded well and was discharged to finish her treatment at home.

After surgery, however, the patient started having irregular, long menstrual cycles (approximately 50 days) and light menstrual flows. She looked for gynecological care and was referred to fertility preservation.

She came to the Human Reproduction Center with her mother and produced the following tests: $\mathrm{FSH}$ $=10.2 \mathrm{mUI} / \mathrm{mL} ; \quad \mathrm{LH}=8.02 \mathrm{mUI} / \mathrm{mL} ; \mathrm{PRL}=9.4 \mathrm{ng} /$ $\mathrm{mL} ; \mathrm{TSH}=2.52 \mathrm{mUI} / \mathrm{mL} ; \mathrm{E}=4 \mathrm{pg} / \mathrm{mL} ; P=1.0 \mathrm{ng} / \mathrm{mL}$. Transvaginal ultrasound showed the same complex formation in the right adnexa; ovarian reserve could not be assessed by antral follicle count on this side. On the left side (not affected) her antral follicle count was normal - 10 follicles. Both tests were performed on day two of her menstrual cycle.

Surprisingly, a test ordered at our center revealed her AMH levels were low $(0.5 \mathrm{ng} / \mathrm{mL}$ - reference value $1.5-4 \mathrm{ng} /$ $\mathrm{mL}$ ). After discussing the case, the staff presented to the patient and her family the possibility of performing a fertility preservation procedure consisting of storing ovarian fragments.

The case report in question was approved by the Research Ethics Committee of the University of Ribeirão Preto and was given permit no. 40670414.4.0000.5498. The patient formally consented to the publication of her case. 


\section{DISCUSSION}

This paper reports the case of a teenager diagnosed with mesenteric lymphadenitis facing a drastic reduction in her ovarian reserve. It also includes an assessment of the chances of her becoming pregnant in the future and the fertility preservation measures proposed by the attending medical staff.

The patient had lymphadenitis in the right abdominal region accompanied by suppurative local lymph nodes. The surgeons carried out a laparotomy and were careful not to remove the patient's right ovary. They suspected, however, that the suppurative nodes had affected the patient's ipsilateral ovary, resulting in ovarian cortex necrosis and fibrosis with loss of function.

As there was no other explanation for her low levels of $\mathrm{AMH}$, the patient was considered to have ovarian function impairment due to suppurative adjacent mesenteric lymph nodes. The medical staff opted to offer her elective cryopreservation of gametes. Cryopreservation of ovarian tissue is performed more urgently in individuals aged 30 years and older, once the depletion of the remaining oocytes occurs at a much faster pace in women in this age range.

The evaluation of the patient's reproductive status and the ensuing indication for fertility preservation raised some questions: would she be able to get pregnant spontaneously (?); was mesenteric lymphadenitis the only entity responsible for the reduction of her ovarian reserve or would the patient evolve to premature ovarian failure, regardless of the inflammatory process (?); were both or only one of her ovaries functioning (?); should the patient be considered to have a single ovary (?); and finally, what were the patient's real possibilities of benefiting from fertility preservation and by what means?

Wallace et al. (2014) discussed fertility preservation indications for children and teenagers with cancer submitted to chemotherapy. In cases of cancer, there is urgency in performing fertility preservation procedures because of the aggressive nature of cancer therapies, a condition not observed in this case. According to the American Society of Clinical Oncology (ASCO) and the American Society for Reproductive Medicine (ASRM), there is no consensus over the use of ovarian tissue cryopreservation for non-cancer patients. Nevertheless, Garcia et al., 2007, described the following criteria for fertility preservation: individuals aged 42 years or younger; absence of previous chemotherapy and radiotherapy in the treatment; realistic chances of long survival after treatment; increased risk of immediate ovarian failure; negative serology for HIV and hepatitis; absence of children. Based on these criteria, our patient was believed to be a good candidate for fertility preservation.

The preservation of the patient's reproductive and hormonal function constitutes the most important point of this paper, once the patient was a teenager with a disease that could result in infertility. The main question, therefore, is why ovarian tissue cryopreservation was chosen as the method to preserve her reproductive function (Modotte et al., 1998).

If the patient were a child, hormonal stimulation would certainly be contraindicated. As the patient was a teenager, there were doubts as to whether she should be offered ovarian tissue cryopreservation, cryopreservation of immature oocytes for in vitro maturation (IVM), or cryopreservation of mature oocytes (after hormonal stimulation), although the last option is more commonly offered to adult patients. According to Tapia et al., 2010, immature oocyte cryopreservation has not produced satisfactory results. Therefore, ovarian tissue cryopreservation seemed to be the most appropriate technique.
Patients with a single ovary are known to enter menopause earlier (Silva, 2006), but so far there has been no formal indication for gamete preservation for them. In Brazil freezing oocytes for convenience is allowed, and one must thus consider advising patients with a single ovary or individuals submitted to abdominal-pelvic surgeries at risk of having their ovaries damaged of the possibility of having their oocytes frozen to preserve their future reproductive life.

Premature ovarian failure (POF) is described as hypergonadotropic hypogonadism accompanied by amenorrhea in women under 40 years of age. Incidence among women of reproductive age ranges from one to three percent (Slopien \& Warenik-Szymankiewicz, 2014) but it has been estimated that $90 \%$ of the cases of POF remain undiagnosed (Udgaonkar et al., 2015). The main causes are chromosomal alterations such as Turner syndrome, fragile $X$, balanced autosomal translocation, and a number of autoimmune diseases (Wang et al.,2015). The patient described in this case report underwent genetic evaluation, which ruled out the most important genetic causes of POF.

We conclude that clearer selection criteria for fertility preservation in non-cancer patients are required. As a suggestion, patients with a single ovary without the conditions or the intention to get pregnant for the next five to ten years, depending on their age, should be encouraged to have their oocytes frozen.

\section{Acknowledgements}

The authors would like to thank the staff of the Hospital Electro Bonini and the Human Reproduction Center of the Ana Bartmann Clinic for their invaluable help.

\section{CONFLICT OF INTERESTS}

No conflict of interest have been declared.

\section{Corresponding author:}

Ana Karina Bartmann

Centro de Reprodução Humana - Hospital Electro Bonini

Ribeirão Preto/SP

E-mail: clinica@anabartmann.com.br

\section{REFERENCES}

Asano S. Granulomatous Lymphadenitis. J Clin Exp Hematopathol 2012; 52:1-16.

Backhus LE, Kondapalli LA, Chang RJ, Coutifaris C, Kazer R, Woodruff TK. Oncofertility Consortium Consensus Statement: Guidelines for Ovarian Tissue Cryopreservation. Cancer Treat Res. 2007; 138: 235-9.

Bertelli L, Masetti R, Bardasi G, Maretti M, Gargano T, Corsini I, Melchionda F, Tassinari D, Cazzato S, Lima M, Pession A. Two Case of Abdominal Pain in Children with Mesenteric Lymphadenitis due to Yersinia pseudotuberculosis Infection. J Pediatr. 2014; 165:411-411.e1

Bratucu E, Lazar AM, Marincas M, Daha C, Zurac S. Aseptic mesenteric lymph node abscesses. In search of an answer. A new entity? Chirurgia. 2013; 108:152-60.

Dare FO, Makinde OO, Makinde ON, Odutayo R. Congenital absence of an ovary in a Nigerian woman. Int J Gynaecol 1989; 29:377-8.

Garcia R, Velez J, Reis C, Porto A. [Tuberculosis presenting with abdominal lymphadenitis]. Medicina Interna 2007; $14: 72-6$.

Groselj-Grenc MG, Repse S, Vidmar D, Derganc M. Clinical 
and Laboratory Methods in Diagnosis of Acute Appendicitis in Children. Croat Med J. 2007; 48:353-61.

Karmazyn B, Werner E, Rejaie B, Appleagate K. Mesenteric lymph nodes in children: What is normal? Pediatr Radiol. 2005; 35: 774-7.

Kovanci E, Schutt AK. Premature Ovarian Failure: Clinical Presentation and Treatment. Obstet Gynecol Clin North Am. 2015; 42:153-61.

Liao WH, Wang HY, Liou TC. Acute mesenteric adenitis mimicking appendicitis in an HIV patient. Intern Med. 2011;50:783

Lucey BC, Stuhfaut FW, Soto JA. Mesenteric lymph nodes seen at imaging: causes and significance. Radiographics. 2005;25: 351-65.

Martins CLS, Gandolfi L, Tauil PL, Picanço MAR, Araujo MOG, Pratesi R. [Celiac disease and female infertility: a frequently neglected association] Rev Bras Ginecol Obstet. 2006; 28: 601-6.

Modotte W, Dias R, Filho C, Lima C, Junior D, Barreiros F. Achados Laparoscópicos na In- fertilidade J Bras Ginecol. 1998; 108:121-4.

Tapia O, Villaseca M, Araya JC. [Mesenteric cryptococcal lymphadenitis: report of one case]. Rev Med Chil. 2010;138:1535-8

Silva ACJSR. [Fertility preservation]. Rev Bras Ginecol Obstet 2006; 28:365-72.

Slopien R, Warenik-Szymankiewicz A. Premature ovarian failure: diagnosis and treatment. Clin Exp Obs Gynecol 2014; 41: 659-61.

Udgaonkar US, Patil SS, Rekha VB, Shah S. Suppurative supraclavicular bacille calmette-guerine lymphadenitis - A case report, awareness and management options. Indian J Med Microbiol 2015; 33:137-9.

Wallace WH, Smith AG, Kelsey TW, Edgar AE, Anderson RA. Fertility preservation for girls and young women with cancer: population-based validation of criteria for ovarian tissue cryopreservation. Lancet Oncol 2014;15: 129-36.

Wang $\mathrm{H}$, Chen $\mathrm{H}$, Qin $\mathrm{Y}$, Shi Z, Zhao X, Xu J, Ma B, Chen ZJ. Risks associated with premature ovarian failure in Han Chinese women. Reprod Biomed Online. 2015; 30:401-7 